\title{
Reactive Power Compensation Strategies in Power System Engineering
}

\author{
Ajayi.A ${ }^{1}$, Izuagie F.I ${ }^{2}$ Jerome D.K ${ }^{3}$ \\ ${ }^{1,2,3}$ Department Of Electrical/Electronics Engineering Auchi Polytechnic,Auchi Edo State,Nigeria.
}

\begin{abstract}
The poverty of lagging power factors at which large industrial loads operate often leads to poor voltage regulation. When a transmission line is lightly loaded there is always the danger of over-voltage at the receiving end due to the well-known phenomenon called "Ferranti effect". In both cases, reactive power demand is often much higher than when load power factors are maintained at unity or close to unity. It becomes more expensive than necessary for Supply Authorities to generate and supply the needed electrical energy, if reactive power compensation strategies are not adopted and enforced. It explains why consumers suffer low voltage supply in most cases, especially where supply Authorities are unable to cope. This paper aims at highlighting such indispensable compensation strategies for serious reconsideration and due application by the country's giant Supply Authority (PHCN), for the purpose of sustainable national development. To this end, the writers have used the Irrua-Agenebode 33kv transmission line as a case study. The extensive use of capacitor banks at all primary distribution (33/11KV) substations is strongly recommended amongst other things.
\end{abstract}

Keywords: reactive power, Ferranti effect, lagging power factor

\section{Introduction}

Reactive power is the Wattless component of the total electrical power. It is apparently worthless, but constitutes a necessary accompaniment to the transfer of the real or active power. To a very large extent, the variation of power system voltage under normal operational conditions is a direct function of the variation of reactive power flow in the transmission line system (FRANCIS T.G,1971). Therefore, reactive power compensation strategies involve all the measures adopted in practice for the generation or absorption of reactive power as need arises in a transmission network in order to maintain the system voltage regulation within acceptable limits.

Voltage regulation is defined as the change in voltage from no-load to full-load, expressed on the base of the full-load voltage. Usually the maximum voltage regulation of low and medium voltage transmission lines is $10 \%$. For extra-high and high-voltage lines it is nearer 5\%, and it is possible in practice to operate lines with zero regulation (LAITHWAITE \& FRERIS, 1980). The desirability of low values of voltage regulation becomes evident from the analytical fact that large voltage differences at the two ends of transmission line give rise to large reactive power transfer, high transmission losses, and reduction of active power transfer capability (JONES.B.1972).

For this reason, most electricity utility tariff structures include some form of cost penalty against consumers who would operate at poor power factor levels; thus, making it mandatory for such consumers' (chiefly industrialists) to adopt measures necessary to correct their load power factor (i.e. to improve upon the ratio of active to apparent power which is usually designated, cos. $\varnothing$ ). A load at 0.95 power factor, for instance, implies a reactive power demand of $0.33 \mathrm{KVAr} / \mathrm{KW}$ (WEEDY, 1979). In practice, this is considered a good power factor. But most industrial loads especially where induction motors are predominate, operating at as poor a power factor as 0.7 lagging; implying a reactive power demand of not less than $0.4 \mathrm{KVAr} / \mathrm{KW}$ of power per load, by extrapolation. Thus, apart from the two-part tariff usually imposed on industrial consumers, there is also an imposition of $1 \%$ increase in cost for each $\mathrm{KW}$ of maximum power demand for every 0.01 by which the average lagging power factor for the year of supply is less than 0.9, for instance (FRANCIS, 1971).

Reactive power compensation strategies, which invariably have to do with power factor correction, include.

(i) Static Compensation (ii) Synchronous Compensation

These are effectively discussed in the sections that follow.

\section{Static Compensation Strategies}

By static compensation strategies is meant all the reactive power compensation measures involving no rotating mechanical parts in their basic design or arrangement. They come under series and shunt compensation strategies, compensation by reactive loading of transformers, saturable reactor compensation method, and compensation by tap changing of transformer. 


\section{Series Compensation Strategy:}

Series compensation has to do essentially with the series connection of capacitor banks at intermediate points of long overhead lines for reduction of the inductive reactance along the line between the supply point and the load the bank consist of a series/parallel connection of capacitor units which might be rated at about $60 \mathrm{NF}, 1 \mathrm{KV}, 20 \mathrm{~A}$ (20KVA) each.

One major draw back of this strategy is the high over-voltage produced when a short-circuit current flows through the capacitor bank therefore, spark gaps are usually incorporated, as protective devices, designed to break down when excessive voltage appears across the bank. It improves voltage regulation, enhances transmission capacity of extra-high voltage systems, thus permitting a higher loading capacity per right of way. And also decreases load voltage fluctuation. Owing to electric welders, arc furnaces, etc by reducing the angular swings caused by such disturbances.

\section{Shunt Compensation Strategies:}

These involve the use of shunt-connected reactors or capacitor banks.

\section{Shunt-Connected Capacitor Banks:}

These are capacitor banks connected in parallel with transmission or, more so, distribution lines either at their terminal substation buses or at the very buses of the load system. They also comprise series/parallel connection of capacitor units, which might be rated at about 1uf, 10kv, 3a (30kva) each (JONES, 1972). Protection against failure of capacitor units must be provided. This is usually accomplished by the connection of voltage transformer between equipotential points under normal condition, so that occurrence of unbalance will cause appropriate circuit-breaker action.

\section{Shunt-Connected Reactors:}

Shunt-connected reactors are used in long transmission lines to improve system stability by providing steady-state voltage control and reduction of switching surge over-voltage. Reactors are VAr absorbing devices. When the lines are lightly loaded during the off-peak periods, the voltage increases to excessive value due to the charging (or leading) current. The shunt reactors, by taking lagging current do cancel the capacitive or charging current in the lines to restore normal voltage.

The required size of reactor unit depends indeed on the application optimum compensation of a long $275 \mathrm{kv}$ cable circuit, for example, requires 50MVAr units approximately every $5 \mathrm{~km}$ (JONES,1972). The size of reactors for general voltage control purposes depends on the short-circuit power of the network. According to JONES, for a value of 15GVA and a permissible step voltage change OF $2 \%$ A 300MVAr unit is allowed.

\section{Reactive Loading Of Transformers}

Compensation by reactive loading of existing transformers consist in the connection of reactors or capacitor banks to the tertiary (delta) winding of main existing transformers for voltage control purposes. Tertiary windings have voltage rating of the order of $11 \mathrm{kv}$. As the reactors or capacitor banks will normally have to be switched. The cost of switching at $11 \mathrm{kv}$ is obviously far below that of switching at an extra-high voltage (EHV) of $330 \mathrm{kv}$, for example, here lies the advantage of this strategy. More so, compensators (1.4 reactors and capacitors) are cheaper per MVAr at $11 \mathrm{kv}$ than at EHV.

Reactor loading is required only at times of low real power on long EHV lines to combat Ferranti effect. Other wise continuous loading requirement could mean installation of more expensive transformers. Figure (1) is an illustration of reactor loading of a main transformer. The adoption of earth free arrangement in the $11 \mathrm{kv}$ circuit.

Motors, which respond to relays set to hold the voltage at the prescribed level on the transformer lowvoltage side. The range of voltage level adjustment by this strategy is usually $\pm 10 \%$ (TEVENSON, Jr., 1975). Figure 3 is an illustration of a tap-changing transformer in application. A complex power demand on node 3 is supplied from an alternator through a transmission line reactance $\mathrm{X}_{\mathrm{L}}$ and a tap-changing transformer of reactance, $\mathrm{X}_{\mathrm{T}}$. We will take for granted that the voltage of node 1 is maintained constant by the action of the alternator automatic voltage regulator. and that the transformer reactance $\mathrm{X}_{\mathrm{T}}$ is the same on all taps.

When $\mathrm{Q}_{\mathrm{d}}$ increases, $\mathrm{V}_{3}$ and $\mathrm{V}_{2}$ will drop by $\Delta \mathrm{V}_{3}$ and $\mathrm{V}_{2}$ respectively., The automatic tap-changing mechanism will then increase $\mathrm{V} 3$ to the original value, thus enhancing the load reactive power demand and the voltage drop at node2 which will now be $\Delta \mathrm{V}^{1}{ }_{2}\left(\Delta \mathrm{V}^{1}{ }_{2}>\Delta \mathrm{V}_{2}\right)$. It follows that the tap-changing operation maintains the consumer voltage constant at the expense of increased voltage drop at the transformer primary. This is permissible however, within certain limits, as excessive reduction of $\mathrm{V}_{2}$ could lead to voltage instability.

For a line of a given reactance, there is a maximum power transfer to a load of a given power factor. With large value of $X_{1}$ and $X_{t}$ and for a power factor, a situation may arise where transformer tapping-up action will produce a fall rather than a rise in secondary voltage (LAITHWAITE \& FREIS, 1980). In a well-designed 
power system, measure will be taken to support $\mathrm{V}_{2}$ by injecting reactive power at node 2 or 3 from a capacitor or a synchronous compensator long before such an eventuality is reached.

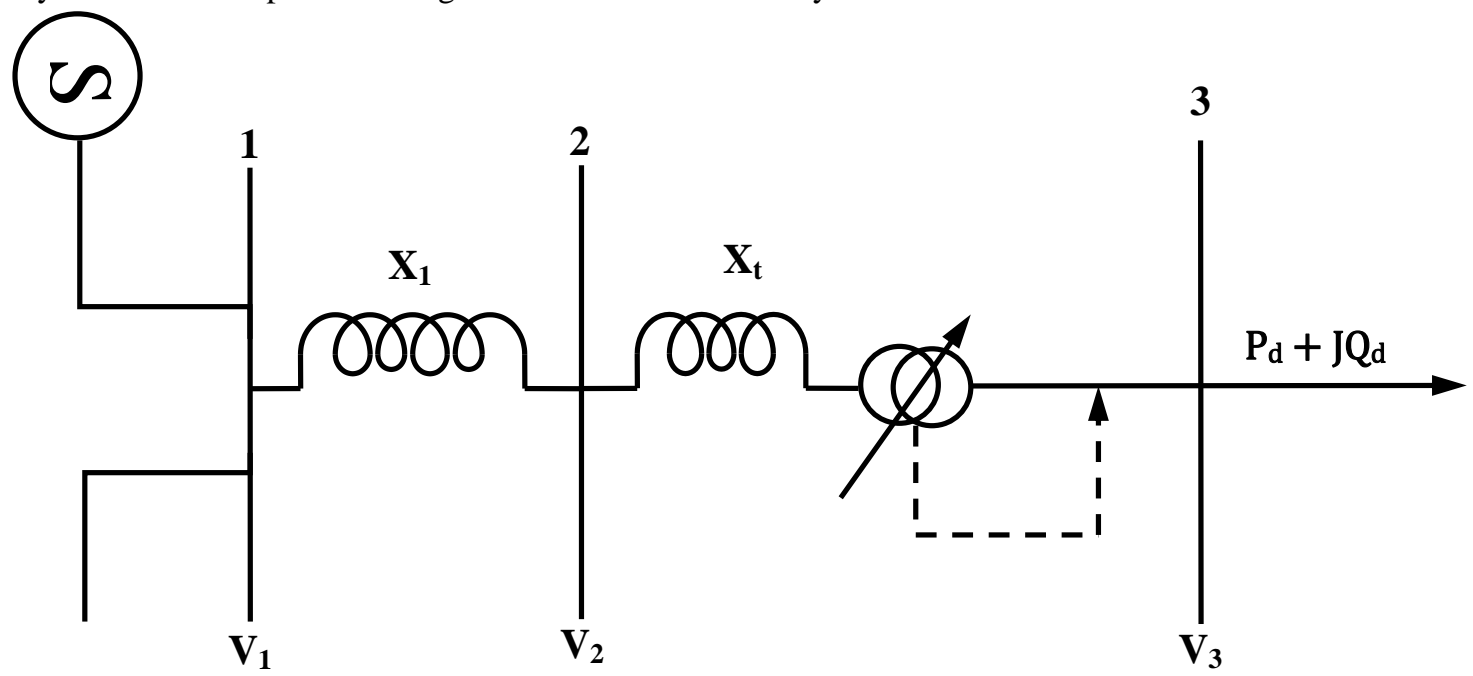

FIG. 1: Tap-changing Transformer in Application

\section{Saturable Reactor Compensation}

A saturable iron-cored reactor has a high inductance and low reactive power absorption provided the applied voltage is below a critical value. Above this value the apparent inductance fall for part of the cycle, and more reactive power consumed. It follows that a saturable reactor is a regulating device that responds only to changes in its terminal voltage as shown in fig 2 . The device acts as a constant- voltage source up to a limited power output, determined by the rating of the capacitors, $C_{S}$ And $C_{1}$. Above this limit the voltage collapses and full short circuit current is independent of the device used at a distribution supply point the device suppresses voltage fluctuations caused by surges of reactive power demand (e.g. for motor starting, are welding etc.) when used at intermediate points on a long transmission line the stability limits are greatly improved. But it has to be noted that since the device contains inductors and capacitors resonating at $50 \mathrm{~Hz}$, the time of response is determined by the damping of the circuit. A fast response is made possible by special damping resistor or set of resistors, which will result inevitably however, in continuous power dissipation.

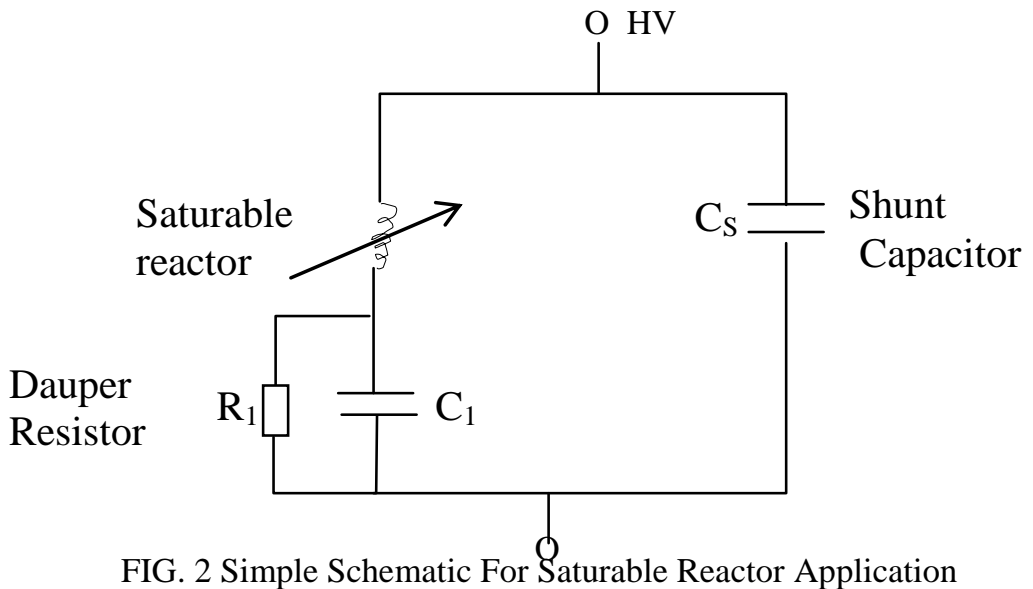

\section{Synchronous Compensation Strategies}

Synchronous generator and synchronous motor compensations are the two strategies involved in this case. This approach to voltage control stems from the fact that variation of the excitation of a synchronous machine gives a significant room for reactive power compensation. For, above or below normal excitation, the machine is capable of either generating or absorbing reactive power. Normal excitation is defined as the excitation to maintain a particular load at unity power factor (G.E.C. MEASUREMENT, 1987).

\section{Synchronous Generator Compensation}

This is indeed a sending-end compensation strategy. When a synchronous generator (or alternator) tied to an infinite bus is over-excited (i.e. excited above normal), it operate at a lagging power factor and behaves 
like an inductor thereby absorbing reactive power (i.e. leading Var) from the network to which it is connected. On the other hand, when it is under-excited (i.e. excited below normal), it operates as a generator or injector of reactive power into the associated network.

The capability of synchronous generators to inject or absorb reactive power is seen to be enhanced by a reduction in the active or real power delivery. It is possible for and alternator to have more than sufficient injection capability to cover the demand at high system load. But the crisis comes at high load when the absorption capability is far less than the reactive power generate by the combined load and network. Additional absorption facility becomes necessary in the form of a synchronous phase modifier if Ferranti effect must be avoided.

\section{Synchronous Motor Compensation}

This is chiefly a receiving-end compensation strategy, though intermediate point application is also practical. A synchronous motor running light, without a mechanical load is often referred to as synchronous compensator or synchronous phase modifier. It is connected in parallel with the load or load center bus at the receiving end of a sub-transmission line. For voltage control of long EHV transmission lines it is usual to connect it to the tertiary. Winding of the main transformer linking the transmission to the sub-transmission system.

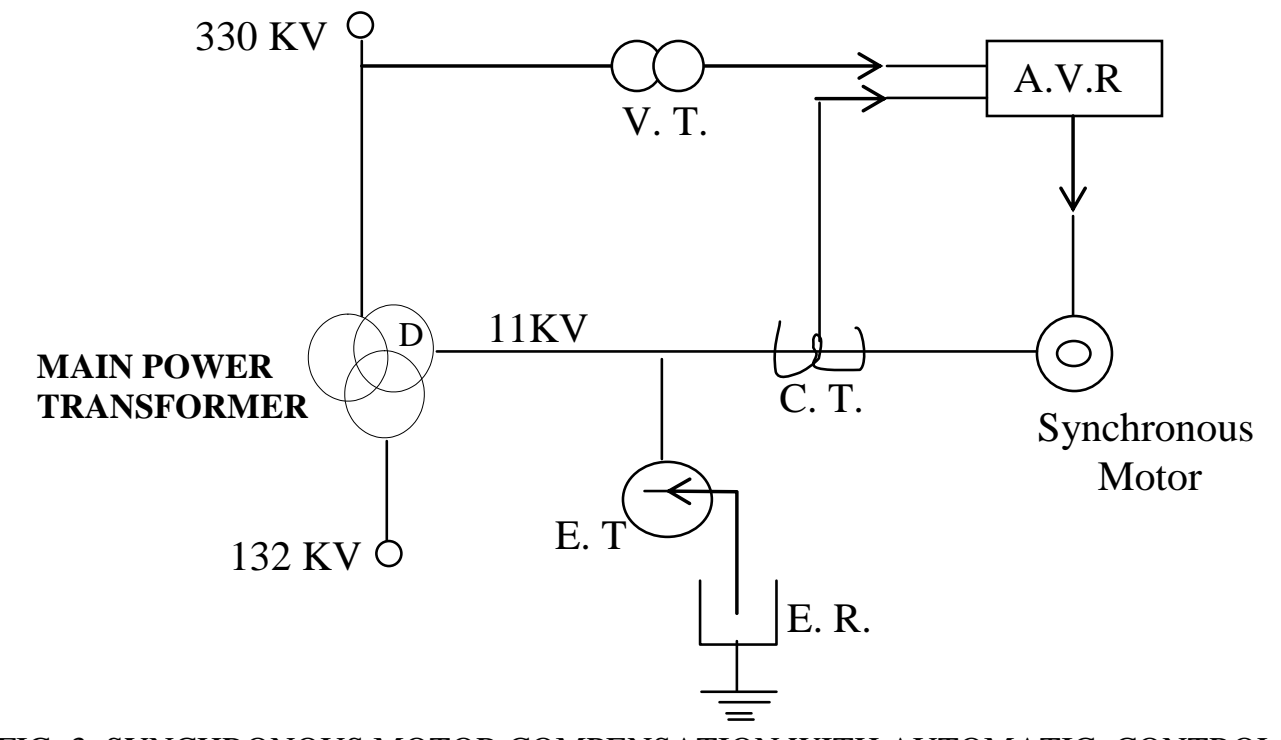

(A. V. R. - Automatic voltage Regulation; V. T - voltage Transformer; C. T. current Transformer; E. T. Earthing Transformer; E. R - Earthing resistor).

When used with a voltage regulator as in figure 3 . The transmission line voltage is controlled through a feed back loop that adjusts the synchronous motor excitation. Then the motor can automatically run overexcited at times of high load to inject reactive power and under excited at light load periods to absorb reactive power from the system.

\section{The Irrua - Agenebode Transmission Line: A Case Study}

The above named line is a short medium -voltage overhead transmission line, being approximately 75 $\mathrm{km}$ long at $50 \mathrm{~Hz}$ and $33 \mathrm{KV}$ in tension (SHEPHERED et al., 1970). This $150 \mathrm{~mm}^{2}$ (Wolf) aluminum-conductors - steel - reinforced line has a resistance and a reactance of approximately $0.19 \mathrm{ohm} / \mathrm{km}$ and $0.34 \mathrm{ohm} / \mathrm{km}$ at $50 \mathrm{~Hz}$ and $20^{\circ} \mathrm{c}$, as determine from Tables. For short lines, of course, the shunt capacitance will normally be neglected, and the equivalent circuit of the line will then consist of a resistance in series with an inductive reactance as shown in fig $4 \mathrm{a}$ and $4 \mathrm{~b}$. 

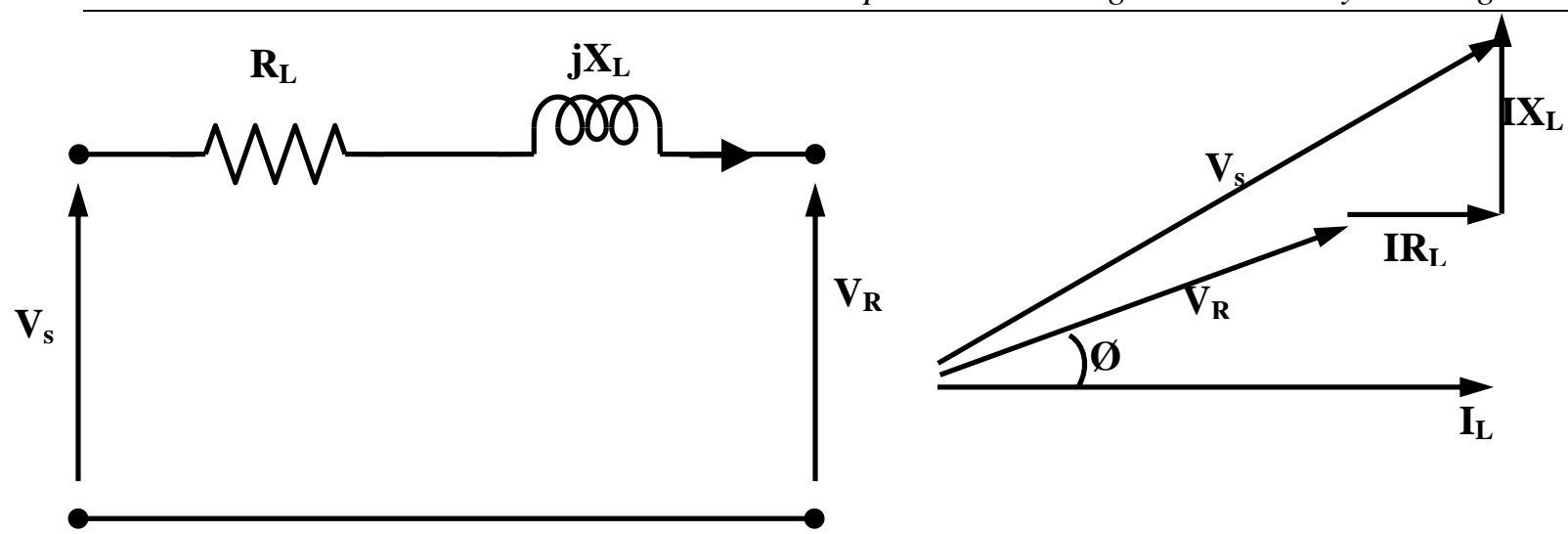

Fig 4 A

Fig 4 B transmission line

Equivalent circuit diagram of the short transmission line Phasor diagram of the short Where

$\mathrm{V}_{\mathrm{S}}$-Sending-end Voltage (at Irrua substation).

$\mathrm{V}_{\mathrm{R}}$ - Receiving-end Voltage (at Agenbode).

$\mathrm{R}_{\mathrm{L}}-$ Resistance of the Line per phase.

$\mathrm{X}_{\mathrm{L}}-$ Reastance of the line per phase

$\mathrm{I}_{\mathrm{L}}-$ Load current on the line.

During the month of study (April 2002) peak load was seen to be as much as $11.3 \mathrm{MW}$ at $329 \mathrm{~A}$ at an approximate power factor of $0.60=\cos \Theta$ lagging.

The Voltage Situation

Impedance drop along the line $\left(\mathrm{V}_{\mathrm{Z}}\right)$

$$
I_{L}\left(R^{2}+X_{L}^{2}\right)^{1 / 2}
$$

$3.29\left[(0.19 X 75)^{2}+(0.34 X 75)^{2}\right]^{1 / 2}$

$9610 \mathrm{~V}$ or $9.60 \mathrm{KV}$ at peak load.

The receiving-end voltage, $V_{R}$

$=V_{S}-V_{Z}=33-9,60=23,4 K V$

The result is that the secondary voltage of the $33 / \mathrm{KV}$ power transformer at the Agenebode primary Distribution substation becomes. $\quad=23.4(11 / 33)=7.8 \mathrm{KV}$

The Line Has A Total Of 16 Load Point Including The Auchi Load Point Shown In The Table Below.

\begin{tabular}{|c|c|c|c|}
\hline $\mathbf{S} / \mathbf{N}$ & IRRUA-AUCHI AXIS & $\begin{array}{ll}\text { VOLTAGE } & \text { LEVEL } \\
(\mathrm{KV}) & \\
\end{array}$ & $\begin{array}{l}\text { RATING }{ }^{\mathrm{KW}} / 100 \times 0.8= \\
\text { AVAL }\end{array}$ \\
\hline i & Bendel feed \& Flour Mill S/S Ewu & $132 / 33 \mathrm{KV}$ & 30MVA \\
\hline ii & Nigeria Advanced School of Theology, Ewu & $33 / 0.414 \mathrm{KV}$ & $200 \mathrm{KVA}$ \\
\hline iii & Benedictive monastery s/s Ewu & $33 / 0.415 \mathrm{KV}$ & 200KVA \\
\hline iv & Juno foods s/s, Agbede & $33 / 11 \mathrm{KV}$ & $2.5 \mathrm{MVA}$ \\
\hline $\mathrm{v}$ & Agbede $2.5 \mathrm{MVA}$ s/s, Agbede & $33 / 11$ & $2.5 \mathrm{MVA}$ \\
\hline vi & Ceven Industries Ltd. Aviele & $33 / 0.415$ & $200 \mathrm{KVA}$ \\
\hline vii & MTN Base Station Aviele & $33 / 0.415$ & 100KVA \\
\hline viii & Alims Industries Aviele & $33 / 0.415$ & $200 \mathrm{KVA}$ \\
\hline ix & Aviele Injection s/s Aviele & $33 / 11$ & $2.5 \mathrm{MVA}$ \\
\hline $\mathrm{x}$ & Aviele Village No 1 s/s Aviele & $33 / 0.415$ & 500KVA \\
\hline $\mathrm{xi}$ & Aviele Village No $3 \mathrm{~s} / \mathrm{s}$ Aviele & $33 / 0.415$ & 500KVA \\
\hline xii & Aviele Village No 4 s/s Aviele & $33 / 0.415$ & $200 \mathrm{KVA}$ \\
\hline xiii & Yak Hotel s/s & $33 / 0.415$ & $300 \mathrm{KVA}$ \\
\hline xiv & PPMC s/s, Aviele & $33 / 11$ & 4MVA \\
\hline $\mathrm{xV}$ & Auchi Poly s/s, Auchi & $33 / 11$ & $2.5 \mathrm{MVA}$ \\
\hline xvi & Hartland s/s Auchi & $33 / 0.415$ & 200KVA \\
\hline
\end{tabular}


The worst voltage level experience on the line.

1. $\quad 24^{\mathrm{th}}$ February, 2008 (a) $20: 45 \mathrm{hrs}$

( $24 \mathrm{kv}$ on the $33 \mathrm{kv}$ line).

2. $\quad 28^{\text {th }}$ March, 2008 (a) 19:03hrs

(24kv on the $33 \mathrm{kv}$ line).

3. $\quad 29^{\text {th }}$ April, 2008 (a) 19:45 hrs

( $24 \mathrm{kv}$ on the $33 \mathrm{kv}$ line).

From the system. The machine is first run up as an induction motor in about 2.5 minutes and then synchronized. Although costly to install, it is justified especially where transmission at power factors less than unity cannot be tolerated, as in long E. H. V. transmission lines. The great advantage of this strategy is also seen in the flexibility of operation for all load conditions.

The corresponding secondary voltage of all nearby $11 / 0415 \mathrm{KV}$ distribution transformer then becomes $=$ $7.8(0.415 / 11)=0.294 \mathrm{KV}$ or 294 volts (of course, those far away will have lesser values).

With this, the domestic voltage supply to residential quarters nearby becomes

$=294 / \sqrt{3}=170$ volts (as against the statutory 240 volts) this is poor indeed!

\section{The Necessary Compensation}

The power factor at peak load $\cos \theta=0.60$ lagging. Although compensation for the realization of unity power factor is possible, it is usually adequate and economical as well to compensate to 0.95 lagging, (IEE Std., 1976), otherwise the cost of compensation may outweigh the gain in cost of the increase active power flow. Now, knowing the MW load and the uncorrected power factor, the compensation MVAr required to achieve a given degree of correction may be calculated from the relation. MVAr (comp.) $=$ MW $\left(\tan \theta_{1}-\tan \theta_{2}\right) \ldots($ G.E.C. MEASUREMENTS, 1987)

$$
\begin{aligned}
& \theta_{1}=\operatorname{COS}^{-1} 0.60=53^{0} \\
& \theta_{2}=\operatorname{COS}^{-1} 0.95=18^{0}
\end{aligned}
$$

$\therefore \operatorname{MVAr}($ comp. $)==11,3\left(\tan 53^{\circ}-\tan 18^{\circ}\right)=11.3$, for a shunt capacitor bank directly connected across the load in question. But at the substation a synchronous compensator or capacitor bank rated $11.3+20 \%$ tolerance (as explained earlier) $=14 \mathrm{MVAr}$ will be required especially a capacitor bank for economic reasons (including low temperature rise and negligible losses). Unfortunately, as at the time of writing neither a synchronous compensator nor a capacitor bank was provide at Agenebode for this purpose, nor at the Auchi primary Distribution $(33 / 11 \mathrm{KV})$ substation between Irrua and Agenebode.

With the above compensation duly effected, the line current $1_{\mathrm{L}}$ will reduce to $(11.3 / \sqrt{ } 3 \mathrm{X} 33 \mathrm{X} 0.95)$ or $208 \mathrm{~A}$, and the impedance drop $\mathrm{V}_{\mathrm{z}}$ becomes $=208\left\{[0.19 \mathrm{X} \mathrm{75}]^{2}+(0.32 \mathrm{X} \mathrm{75})^{2}\right\} 1 / 2=6076 \mathrm{~V}$ or $6.08 \mathrm{KV}$ (meaning $22.6 \%$ of the improved receiving-end voltage, namely $26.9 \mathrm{KV}$ approx.). Therefore, the domestic voltage supply will improve to $195 \mathrm{~V}$, which is better and can be further improved upon by tap-changing of the power transformer at Agenebode so that the domestic voltage comes up to $(195+19.5)=215 \mathrm{~V}$ approx. We see now that the MW capacity of the line increases to $(0.95 / 0.60)^{*} 11.3=17.9 \mathrm{MW}$, implying an increase of $58.4 \%$.

\section{Conclusion And Recommendation}

The dream of president Obasanjo to have the total active power generation increased to 4000MW by December 2001 was no doubt a good dream (THE GUARDIAN, JUNE 29, 2001) if that dream was realized possibly by serious rehabilitation of the existing generation plant as well as proper maintenance work on the transmission and distribution facilities in the power industry, it would have been more than enough to take care of the peak load demand of about 2500MW (UMAR, 2002). In the interim, while plans are still being made towards the realization of the said dream, it is the view of this writer (and strongly so) that with adequate reactive power compensation strategies seriously undertaken Nigerian or the masses of this country will begin to heave a sign of relief in a shorter time than otherwise even with the present state of facilities in the power industry. Although at present PHCN supplies on the average just 30\% of its total installed capacity of approximately 600MW (UMAR, 2002), and assuming the supply at an average load power factor 0.70 lagging, will show that compensating the reactive power supply flow to a power factor degree of 0.95 lagging, the reactive power supply will rise to about $2443 \mathrm{MW}$, i.e. a $35 \%$ rise in MW.

By 1995 , there were $22 \mathrm{~N}$. Of $330 / 132 \mathrm{kv}$ substations, $91 \mathrm{No}$ of $132 / 33 \mathrm{kv}$ substations and 563 No of $33 / 11 \mathrm{kv}$ substation (Umar, 2002). Over the past 7 years the system cannot be said to have changed in the EHV (or main) transmission and the HV (or sub-) transmission substations. But the 33/11KV Primary Distribution substations must be increased in number, and this is where PHCN has failed greatly in the application in number power compensation. It is not enough to have synchronous compensations in many EHV and HV substations, 
even though backed up with compensation alternators. Static shunt capacitor banks are vital in the primary Distribution substations, which are usually close to the load centers. Thus, they should be installed in these substations complete with the NOVAR' capacitor controller, which is a static circuit device providing automatic power factor correction for 3-phase systems, by detecting the leading or lagging VAr's above a preset level (G.E.C. MEASUREMENTS, 1987).

It is further recommended that in the several medium - and small-scale industries in the country in which Primary Distribution substation are not sited PHCN should not only charge extra tariff, but these industries should be compelled to install $415 \mathrm{~V}$, manually switched capacitor banks of enough overalls $\mathrm{VAr}$ rating, especially where induction motors predominate.

\section{References}

[1]. FRANCIS T. G. (1971), Electrical Installation work, Longman Group Ltd., London

[2]. G.E.C. MEASUREMENT (1987), Protective Relays: Application Guide, General Electric Company (Plc) Publication, England.

[3]. IEEE Std. (1976), Recommendation Practice for Electric Power distribution for Industrial plants IEEE Publication, London

[4]. JONES B. (1972), New Approaches to the Design and Economics of EHV Transmission Plant Pergamon press Ltd. Oxford.

[5]. LAITHWAITE \& FRERIS (1980), Electric Energy: its Generation, Transmission and Use, McGraw - Hill (UK) Ltd. London.

[6]. SHEPHERD et at (1970), Higher Electrical Engineering, Pitman Publishing Ltd, London.

[7]. STEVESON W. D., Jr (1975), Elements of Power System Analysis, Mcgraw-Hill, Kogakusha Ltd. Tokyo

[8]. THE GUARDIAN (June 29, 2001), The Solar Energy Option, p. 14, The GuardianNewspaper Publishing Co., Nigeria

[9]. UMAR I. H. (2002), Energy Resources and Development in Nigeria, being a keynote Address Delivered at the Opening of a National Conference on Energy Resources and Development, at Abubakar Tafawa Balewa University, Bauchi, on 11th February 2002.

[10]. WEEBY B. M. (1979), Electrical Power System, John wiley \& Sons Ltd., New York. 